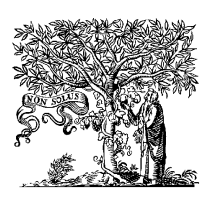

ELSEVIER

Fluid Phase Equilibria 173 (2000) 1-21

www.elsevier.nl/locate/fluid

\title{
A group contribution correlation of the mutual diffusion coefficients of binary liquid mixtures
}

\author{
Yu-Du Hsu, Muoi Tang ${ }^{1}$, Yan-Ping Chen* \\ Department of Chemical Engineering, National Taiwan University, Taipei, Taiwan, Republic of China
}

Received 23 November 1999; accepted 30 May 2000

\begin{abstract}
A group contribution method is developed on the basis of the UNIDIF model [Y.D. Hsu, Y.P. Chen, Fluid Phase Equilibria 152 (1998) 149-168] for the correlation of the mutual diffusion coefficients of binary liquid mixtures. In this group contribution UNIDIF (GC-UNIDIF) model, a mole fraction average of the logarithm of the infinite dilution limiting diffusion coefficients is taken as a reference term. The model expresses the excess part of the diffusion coefficient relative to this reference term in a form similar to that of a UNIFAC equation with two parts due to the combinatorial and residual contributions. The combinatorial part depends on the molecular sizes and shapes. The residual part includes two binary interaction parameters, which are obtained from generalized data regression, for each pair of functional groups. Optimal group interaction parameters are presented. The mutual diffusion coefficients of binary liquid mixtures are calculated for non-polar+non-polar, non-polar+polar and polar+polar fluid mixtures in this study. The calculation results using the GC-UNIDIF model for mutual diffusion coefficient are satisfactory. This model also requires lesser number of parameters than other correlative methods. @ 2000 Elsevier Science B.V. All rights reserved.
\end{abstract}

Keywords: Group contribution; Method of calculation; Diffusion coefficient; Mixture

\section{Introduction}

Diffusion coefficient is essential for the application of chemical and equipment design involving mass transfer processes. Many estimation methods for the diffusion coefficients have been derived. Generally, they express the mutual diffusion coefficient as the product of a compositional average of the limiting diffusion coefficients and a thermodynamic factor that expresses the composition dependence of the activity. The thermodynamic factor is calculated from an activity coefficient model, such as the NRTL model, but the optimal binary interaction parameters in the diffusion coefficient calculations are usually

\footnotetext{
* Corresponding author. Tel.: +886-2263-5230; fax: +886-2362-3040.

E-mail address: ypchen@ccms.ntu.edu.tw (Y.-P. Chen).

${ }^{1}$ Present address: Department of Chemical Engineering, Chinese Culture University, Taipei, Taiwan, Republic of China.
} 
not the same as those obtained from vapor-liquid equilibrium (VLE) data regression [2]. A review of liquid diffusion of non-electrolyte solutions has been presented by Ghai et al. [3]. Cussler [4] proposed a correlative cluster diffusion model, and further applications of this model have been presented by Cullinan [5] and Rollins and Kanebel [6]. Recently, Pertler et al. [7] reviewed various correlation equations for mutual diffusion coefficient and compared them for the binary mixtures that may have liquid phase separation.

On the basis of statistical thermodynamics, Abrams and Prausnitz [8] derived the universal quasichemical (UNIQUAC) model for the activity coefficients of liquid mixtures. Fredenslund et al. [9] employed the solution of functional group approach and developed the UNIFAC (UNIQUAC functional-group activity coefficients) model. The group contribution method determines the thermophysical properties in a generalized way, and this approach is attempted in the calculations of transport properties of fluid mixtures. Based on statistical thermodynamics, Cao and coworkers $[10,11]$ developed models for the viscosities of liquid mixtures. Cao et al. [12] further extended their UNIMOD model to a group contribution UNIMOD (GC-UNIMOD) expression.

On the basis of statistical thermodynamics and absolute reaction rate theory, a correlative UNIDIF model for the mutual diffusion coefficients was developed [1]. Based on the UNIDIF model, the mutual diffusion coefficients are extended to a group contribution method that is also in a local composition form with combinatorial and residual contributions. Molecular size, shape and interaction effects are included in this group contribution model. This model is then applied in calculating the mutual diffusion coefficients of non-polar and polar binary mixtures. Generalized group interaction parameters are reported. The calculation results and comparisons with other methods are also presented in this study.

\section{Development of the mutual diffusion coefficient model}

Cao et al. [10] developed a statistical thermodynamics model for the viscosity of liquid mixtures. A similar approach has been applied for the development of a mutual diffusion coefficient model [1]. According to the lattice theory [13], the partition function of a liquid mixture is written as

$$
\Omega=\Omega^{\mathrm{s}} \prod_{i=1}^{n}\left(\frac{2 \pi m_{i} k T}{h^{2}}\right)^{3 N_{i} / 2} \frac{\omega_{i}}{\omega_{i}^{\mathrm{s}}} \exp \left(-\frac{U_{0 i}}{k T}\right)
$$

where $U_{0 i}$ is the potential energy of component $i$ in a mixture, $n$ is the number of components in a mixture, $N_{i}$ is the number of molecules of component $i, \omega$ is the number of configurations, and superscript $\mathrm{s}$ represents the boundary condition of a Starveman's model. The potential energy $U_{0 i}$ is expressed in a local composition form:

$$
-U_{0 i}=\frac{z q_{i} N_{i}}{2} \sum_{j=1}^{n} U_{j i} \theta_{j i}
$$

The local composition parameter $\theta_{j i}$ is approximated by the equation of Abrams and Prausnitz [8]:

$$
\theta_{j i}=\frac{\theta_{j} \tau_{j i}}{\sum_{l=1}^{n} \theta_{l} \tau_{l i}}
$$


where $\theta_{j}$ is the average fraction of the surface area $q_{j}$ of component $j$ :

$$
\theta_{j}=\frac{x_{j} q_{j}}{\sum_{l=1}^{n} x_{l} q_{l}}
$$

The interaction parameter $\tau_{j i}$ in Eq. (3) is expressed as functions of a Boltzmann factor of the interaction energy $a_{j i}$ and the coordination number $z$ :

$$
\begin{aligned}
\tau_{j i} & =\exp \left(-\frac{a_{j i}}{T}\right) \\
a_{j i} & =\frac{z}{2 k}\left(U_{j i}-U_{i i}\right)
\end{aligned}
$$

The absolute reaction rate theory [14] has been used to describe the transport properties of fluid mixtures. This method states that a molecule traveling between two neighboring equilibrium states has to overcome an energy barrier. The frequency of movement in a fluid mixture is written as

$$
k_{\mathrm{a} m}=\prod_{i=1}^{n}\left(\frac{k T}{2 \pi m_{i}}\right)^{x_{i} / 2} \exp \left(\frac{z}{2 k T} \sum_{i=1}^{n} x_{i} q_{i} \sum_{j=1}^{n} U_{j i} \theta_{j i}\right)
$$

According to the absolute reaction rate theory [14], the diffusion coefficient is proportional to the product of the frequency of movement $\left(k_{\mathrm{a}}\right)$ and the square of the distance between two equilibrium positions $\left(\lambda^{2}\right)$. The diffusion coefficient for a mixture, which is taken as a pseudo-pure fluid, is written as the product of $\lambda_{m}^{2}$ and $k_{\mathrm{a} m}$ from the absolute reaction rate theory. Taking the $k_{\mathrm{a} m}$ in Eq. (7) as an effective specific rate where the non-ideality of the fluid mixture is included in the local composition parameters, the diffusion coefficient is then written as

$$
D=\lambda_{m}^{2} k_{\mathrm{a} m}=\lambda_{m}^{2} \prod_{i=1}^{n}\left(\frac{k T}{2 \pi m_{i}}\right)^{x_{i} / 2} \exp \left(\frac{z}{2 k T} \sum_{i=1}^{n} x_{i} q_{i} \sum_{j=1}^{n} U_{j i} \theta_{j i}\right)
$$

where the distance parameter is assumed to follow the simple mixing rule

$$
\lambda_{m}=\sum x_{i} \lambda_{i}
$$

A multi-component lattice fluid mixture is considered to develop the mutual diffusion coefficient. When two components are interchanging their positions in a mixture, there exist changes in the frequency of movement and the distance of equilibrium position. Parameters $k_{\mathrm{a} m}$ and $\lambda_{m}$ are functions of composition and their derivatives with respect to the composition of component $i$ or $j$ are required to express the effect due to the interchange of molecular positions in the mutual diffusion process. Also, it is assumed that the number of available sites for the movement of component $i$ (or $j$ ) during the mutual diffusion process is proportional to the mole fraction of the other component which interchanges the position with it. The product of the number of available sites for the molecular movement and the derivatives of the frequency or distance parameter with respect to composition gives the effective absolute reaction rate parameters for the mutual diffusion process:

$$
\ln k_{\mathrm{a}, i j}=x_{j}\left[\frac{\partial\left(n \ln k_{\mathrm{a} m}\right)}{\partial n_{i}}\right]_{T, P, n_{k \neq i}}+x_{i}\left[\frac{\partial\left(n \ln k_{\mathrm{a} m}\right)}{\partial n_{j}}\right]_{T, P, n_{k \neq j}}
$$


Table 1

Calculated results of the group contribution method for mutual diffusion coefficients of liquid binary mixtures

\begin{tabular}{|c|c|c|c|c|c|c|c|}
\hline \multirow[t]{2}{*}{ Item } & \multirow[t]{2}{*}{ Group pair } & \multirow[t]{2}{*}{ Points } & \multirow{2}{*}{$\begin{array}{l}\text { Temperature } \\
\text { range }(\mathrm{K})\end{array}$} & \multicolumn{2}{|c|}{ Interaction parameter } & \multirow{2}{*}{$\begin{array}{l}\text { AAD } \\
(\%)^{\mathrm{a}}\end{array}$} & \multirow[t]{2}{*}{ References } \\
\hline & & & & $a_{21}(\mathrm{~K})$ & $a_{12}(\mathrm{~K})$ & & \\
\hline \multirow[t]{10}{*}{1} & $\mathrm{CH}_{2}(1)-\mathrm{CCl}_{4}(2)$ & & & 97.11 & -75.78 & & \\
\hline & 3-Methylpentane+carbon tetrachloride & 6 & 303.15 & & & 0.9 & {$[16]$} \\
\hline & 2,3-Dimethylpentane+carbon tetrachloride & 6 & 303.15 & & & 1.9 & {$[17]$} \\
\hline & 2,2,4-Trimethylpentane + carbon tetrachloride & 6 & 303.15 & & & 1.2 & {$[17]$} \\
\hline & $n$-Hexane+carbon tetrachloride & 12 & $298.15-303.15$ & & & 1.0 & {$[18]$} \\
\hline & $n$-Heptane + carbon tetrachloride & 6 & 303.15 & & & 1.3 & {$[18]$} \\
\hline & $n$-Octane + carbon tetrachloride & 6 & 303.15 & & & 2.7 & {$[17]$} \\
\hline & $n$-Decane+carbon tetrachloride & 4 & 298.15 & & & 3.0 & {$[17,19]$} \\
\hline & $n$-Dodecane+carbon tetrachloride & 4 & 298.15 & & & 1.8 & {$[17]$} \\
\hline & Cyclohexane+carbon tetrachloride & 16 & $298.15-308.15$ & & & 1.1 & {$[20,21]$} \\
\hline \multirow[t]{7}{*}{2} & $\mathrm{CH}_{2}(1)-\mathrm{CHCl}_{3}(2)$ & & & 18.60 & 7.011 & & \\
\hline & n-Hexane+chloroform & 6 & 303.15 & & & 2.0 & {$[16]$} \\
\hline & $n$-Heptane+chloroform & 6 & 303.15 & & & 2.3 & {$[16]$} \\
\hline & $n$-Octane+chloroform & 6 & 303.15 & & & 1.8 & {$[16]$} \\
\hline & 3-Methylpentane+chloroform & 6 & 303.15 & & & 2.9 & {$[16]$} \\
\hline & 2,3-Dimethylpentane+chloroform & 6 & 303.15 & & & 1.2 & {$[16]$} \\
\hline & 2,2,4-Trimethylpentane + chloroform & 6 & 303.15 & & & 1.0 & {$[16]$} \\
\hline \multirow[t]{2}{*}{3} & $\mathrm{CHCl}_{3}(1)-\mathrm{CCl}_{4}(2)$ & & & -62.61 & 94.83 & & \\
\hline & Chloroform + carbon tetrachloride & 12 & 298.15 & & & 1.1 & {$[32]$} \\
\hline \multirow[t]{2}{*}{4} & $\operatorname{DMF}(1)-\mathrm{W}(2)$ & & & 82.42 & 104.9 & & \\
\hline & Dimethylformamide + water & 10 & 278.15 & & & 0.8 & {$[41]$} \\
\hline \multirow[t]{2}{*}{5} & NMP(1)-W(2) & & & 121.4 & 134.4 & & \\
\hline & n-Methylpyrrolidone+water & 10 & 278.15 & & & 3.4 & {$[41]$} \\
\hline \multirow[t]{2}{*}{6} & $\mathrm{CH}_{3} \mathrm{OH}(1)-\mathrm{CCl}_{4}(2)$ & & & 742.3 & 71.49 & & \\
\hline & Methanol+carbon tetrachloride & 11 & 293.15 & & & 8.3 & {$[30]$} \\
\hline \multirow[t]{2}{*}{7} & $\mathrm{CH}_{3} \mathrm{OH}(1)-\mathrm{ACH}(2)$ & & & 606.9 & 70.64 & & \\
\hline & Methanol+benzene & 8 & 313.15 & & & 3.5 & {$[33]$} \\
\hline \multirow[t]{2}{*}{8} & $\mathrm{CH}_{3} \mathrm{OH}(1)-\mathrm{H}_{2} \mathrm{O}(2)$ & & & 260.3 & 53.38 & & \\
\hline & Methanol+water & 25 & $278.15-313.13$ & & & 3.0 & {$[39,40]$} \\
\hline \multirow[t]{4}{*}{9} & $\mathrm{ACH}(1)-\mathrm{CH}_{2}(2)$ & & & 0.3541 & 23.10 & & \\
\hline & Benzene $+n$-hexane & 11 & 298.15 & & & 3.7 & {$[22,23]$} \\
\hline & Benzene $+n$-heptane & 34 & $293.15-358.15$ & & & 4.5 & {$[23]$} \\
\hline & Benzene+cyclohexane & 69 & $293.15-333.15$ & & & 0.9 & {$[24-27]$} \\
\hline \multirow[t]{2}{*}{10} & $\mathrm{CH}_{2} \mathrm{CO}(1)-\mathrm{CH}_{2}(2)$ & & & 371.0 & 153.2 & & \\
\hline & Acetone+cyclohexane & 9 & 298.15 & & & 1.8 & {$[34]$} \\
\hline \multirow[t]{6}{*}{11} & $\mathrm{CH}_{2}(1)-\mathrm{OH}(2)$ & & & 191.0 & 359.8 & & \\
\hline & Cyclohexane+ethanol & 4 & 298.15 & & & 12.7 & {$[35]$} \\
\hline & Cyclohexane $+n$-propanol & 4 & 298.15 & & & 14.6 & [35] \\
\hline & Cyclohexane $+n$-butanol & 4 & 298.15 & & & 18.4 & [35] \\
\hline & Cyclohexane $+n$-pentanol & 4 & 298.15 & & & 17.0 & [35] \\
\hline & Cyclohexane $+n$-hexanol & 4 & 298.15 & & & 18.8 & {$[35]$} \\
\hline
\end{tabular}


Table 1 (Continued)

\begin{tabular}{|c|c|c|c|c|c|c|c|}
\hline \multirow[t]{2}{*}{ Item } & \multirow[t]{2}{*}{ Group pair } & \multirow[t]{2}{*}{ Points } & \multirow{2}{*}{$\begin{array}{l}\text { Temperature } \\
\text { range }(K)\end{array}$} & \multicolumn{2}{|c|}{ Interaction parameter } & \multirow{2}{*}{$\begin{array}{l}\text { AAD } \\
(\%)^{\mathrm{a}}\end{array}$} & \multirow[t]{2}{*}{ References } \\
\hline & & & & $a_{21}(\mathrm{~K})$ & $a_{12}(\mathrm{~K})$ & & \\
\hline & Cyclohexane $+n$-heptanol & 4 & 298.15 & & & 18.0 & {$[35]$} \\
\hline & Cyclohexane $+n$-octanol & 4 & 298.15 & & & 14.9 & [35] \\
\hline & Methylcyclohexane+ethanol & 4 & 298.15 & & & 17.4 & {$[35]$} \\
\hline & Methylcyclohexane $+n$-propanol & 4 & 298.15 & & & 6.7 & [35] \\
\hline & Methylcyclohexane $+n$-butanol & 4 & 298.15 & & & 4.8 & {$[35]$} \\
\hline & Methylcyclohexane $+n$-pentanol & 4 & 298.15 & & & 5.0 & {$[35]$} \\
\hline & Methylcyclohexane $+n$-hexanol & 4 & 298.15 & & & 6.2 & [35] \\
\hline & Methylcyclohexane $+n$-heptanol & 4 & 298.15 & & & 4.9 & [35] \\
\hline & Methylcyclohexane $+n$-octanol & 4 & 298.15 & & & 10.0 & {$[35]$} \\
\hline \multirow[t]{2}{*}{12} & $\mathrm{COO}(1)-\mathrm{CH}_{2}(2)$ & & & 473.0 & 188.0 & & \\
\hline & Ethyl acetate+cyclohexane & 9 & 293.15 & & & 13.4 & {$[24]$} \\
\hline \multirow[t]{2}{*}{13} & $\mathrm{ACCH}_{2}(1)-\mathrm{ACH}(2)$ & & & 18.60 & 456.8 & & \\
\hline & Toluene + benzene & 18 & $293.15-313.15$ & & & 0.6 & [28] \\
\hline \multirow[t]{2}{*}{14} & $\mathrm{CHCl}_{3}(1)-\mathrm{ACH}(2)$ & & & -59.09 & 83.68 & & \\
\hline & Chloroform+benzene & 27 & $298.15-328.15$ & & & 0.5 & {$[28]$} \\
\hline \multirow[t]{3}{*}{15} & $\mathrm{CH}_{2} \mathrm{CO}(1)-\mathrm{CCl}_{4}(2)$ & & & 275.3 & -3.175 & & \\
\hline & Acetone + carbon tetrachloride & 12 & 298.15 & & & 2.2 & {$[31,36]$} \\
\hline & Methyl ethyl ketone + carbon tetrachloride & 7 & 298.15 & & & 3.8 & {$[29]$} \\
\hline \multirow[t]{2}{*}{16} & $\mathrm{CH}_{2} \mathrm{CO}(1)-\mathrm{ACH}(2)$ & & & 183.2 & 5.406 & & \\
\hline & Acetone+benzene & 31 & 298.15 & & & 1.5 & {$[6,27,36]$} \\
\hline \multirow[t]{2}{*}{17} & $\mathrm{CH}_{2} \mathrm{CO}(1)-\mathrm{CHCl}_{3}(2)$ & & & 118.8 & -83.65 & & \\
\hline & Acetone+chloroform & 43 & $298.15-328.15$ & & & 2.3 & {$[27,31,37,38]$} \\
\hline \multirow[t]{4}{*}{18} & $\mathrm{OH}(1)-\mathrm{CCl}_{4}(2)$ & & & 544.6 & -34.68 & & \\
\hline & Ethanol+carbon tetrachloride & 9 & 298.15 & & & 13.7 & [29] \\
\hline & $n$-Propanol+carbon tetrachloride & 11 & 293.15 & & & 4.8 & {$[30]$} \\
\hline & $n$-Butanol+carbon tetrachloride & 11 & 293.15 & & & 10.1 & {$[30]$} \\
\hline \multirow[t]{2}{*}{19} & $\mathrm{OH}(1)-\mathrm{ACH}(2)$ & & & 617.4 & 199.3 & & \\
\hline & Ethanol+benzene & 27 & $298.15-313.13$ & & & 4.5 & {$[31]$} \\
\hline \multirow[t]{3}{*}{20} & $\mathrm{ACCH}_{2}(1)-\mathrm{CH}_{2}(2)$ & & & 8.928 & 108.0 & & \\
\hline & Toluene+cyclohexane & 27 & $298.15-328.15$ & & & 0.9 & {$[28]$} \\
\hline & Grand average & 589 & & & & 3.6 & \\
\hline
\end{tabular}

$$
\begin{aligned}
& { }^{\mathrm{a}} \operatorname{AAD}(\%)=(100 / n) \sum_{i=1}^{n}\left|\left(D_{12, i}^{\mathrm{cal}}-D_{12, i}^{\mathrm{exp}}\right) / D_{12, i}^{\mathrm{exp}}\right| . \\
& \ln \lambda_{i j}=x_{j}\left[\frac{\partial\left(n \ln \lambda_{m}\right)}{\partial n_{i}}\right]_{T, P, n_{k \neq i}}+x_{i}\left[\frac{\partial\left(n \ln \lambda_{m}\right)}{\partial n_{j}}\right]_{T, P, n_{k \neq j}}
\end{aligned}
$$

where $k_{\mathrm{a} m}$ and $\lambda_{m}$ are expressed by Eqs. (7) and (9) for a mixture, respectively. The mutual diffusion coefficient for a multi-component mixture is then written analogously to Eq. (8) as 


$$
\begin{aligned}
\ln D_{j i}= & \ln D_{i j}=2 \ln \lambda_{i j}+\ln k_{\mathrm{a}, i j} \\
= & 2\left(x_{j} \ln \lambda_{i}+x_{i} \ln \lambda_{j}\right)+\frac{1}{2}\left(x_{j} \ln \frac{k T}{2 \pi m_{i}}+x_{i} \ln \frac{k T}{2 \pi m_{j}}\right)+\frac{z}{2 k T}\left(x_{j}^{\left(i_{0}\right)} q_{i} U_{i i}+x_{i}^{\left(j_{0}\right)} q_{j} U_{j j}\right) \\
& -2\left\{x_{j}\left(\ln \frac{\phi_{i}}{x_{i}}-\frac{\phi_{i}}{x_{i}}+1\right)+x_{i}\left(\ln \frac{\phi_{j}}{x_{j}}-\frac{\phi_{j}}{x_{j}}+1\right)\right\} \\
& +\frac{1}{T}\left\{x_{j} q_{i} \sum_{k=1}^{n}\left[a_{k i} \theta_{k i}+\tau_{i k} \theta_{k k} \sum_{l=1}^{n} \theta_{l k}\left(a_{i k}-a_{l k}\right)\right]\right. \\
& \left.+x_{i} q_{j} \sum_{k=1}^{n}\left[a_{k j} \theta_{k j}+\tau_{j k} \theta_{k k} \sum_{l=1}^{n} \theta_{l k}\left(a_{j k}-a_{l k}\right)\right]\right\}
\end{aligned}
$$

where $\phi_{l}(l=i, j)$ is defined as

$$
\phi_{l}=\frac{x_{l} \lambda_{l}}{\sum_{k=1}^{n_{t}} x_{k} \lambda_{k}}
$$

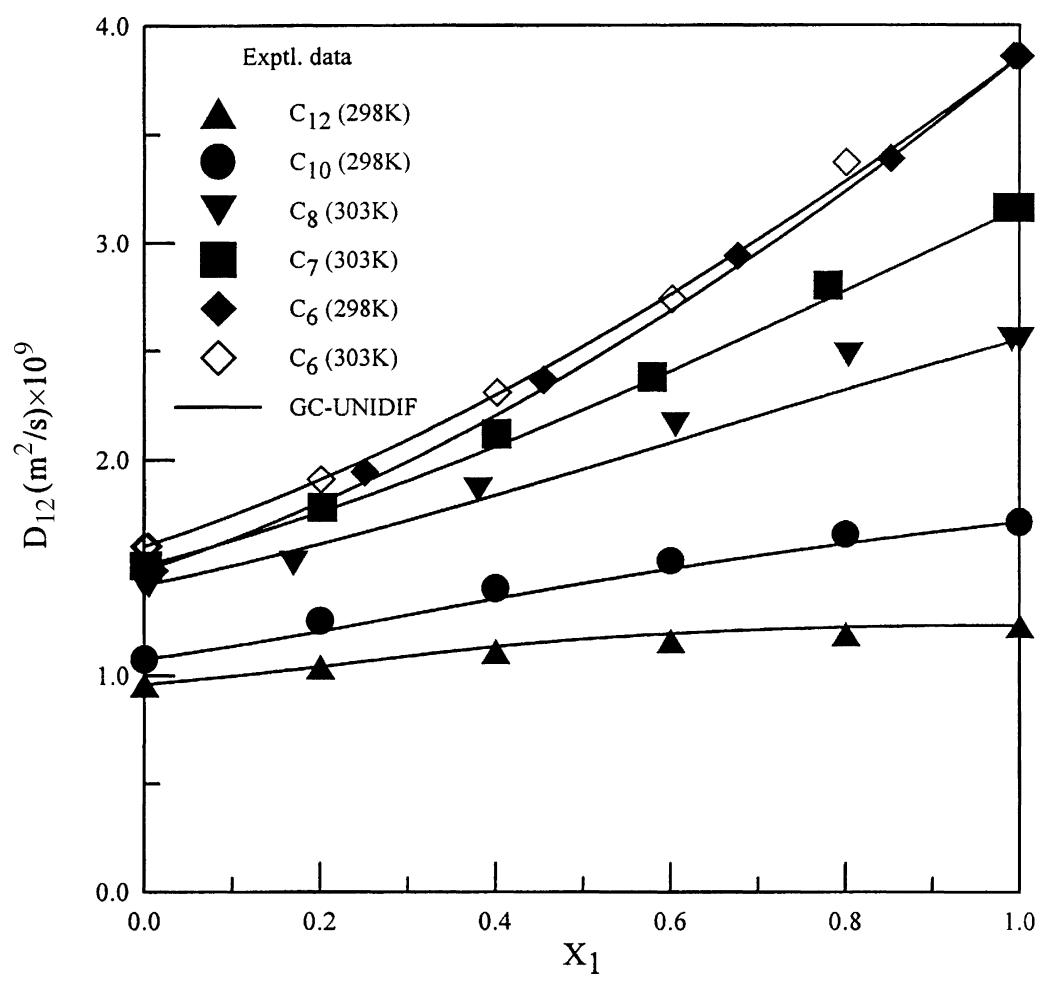

Fig. 1. Calculated results for the mutual diffusion coefficients of binary mixtures of $n$-alkanes (1)+carbon tetrachloride (2) at various temperatures. Data from [16-18]. 
At the limiting condition of infinite dilution, the diffusion coefficient for component $i$ in a multi-component liquid mixture is obtained from Eq. (12) at $x_{i}$ equal to 0 :

$$
\begin{aligned}
\ln D_{i}^{0}= & 2 x_{j}^{\left(i_{0}\right)} \ln \lambda_{i}+\frac{1}{2} x_{j}^{\left(i_{0}\right)} \ln \frac{k T}{2 \pi m_{i}}+\frac{z}{2 k T} x_{j}^{\left(i_{0}\right)} q_{i} U_{i i}-2 x_{j}^{\left(i_{0}\right)}\left(\left.\ln \frac{\phi_{i}}{x_{i}}\right|_{x_{i} \rightarrow 0}-\left.\frac{\phi_{i}}{x_{i}}\right|_{x_{i} \rightarrow 0}+1\right) \\
& +\frac{1}{T} x_{j}^{\left(i_{0}\right)} q_{i} \sum_{k=1}^{n}\left[a_{k i} \theta_{k i}^{\left(i_{0}\right)}+\tau_{i k} \theta_{k k}^{\left(i_{0}\right)} \sum_{l=1}^{n} \theta_{l k}^{\left(i_{0}\right)}\left(a_{i k}-a_{l k}\right)\right]
\end{aligned}
$$

Based on these expressions, the mutual diffusion coefficient of a multi-component mixture is expressed in terms of the limiting values and the following composition dependence:

$$
\ln D_{j i}=\ln D_{j i}^{\mathrm{REF}}+\ln D_{j i}^{\mathrm{EX}}=\ln D_{j i}^{\mathrm{REF}}+\ln D_{j i}^{\mathrm{EC}}+\ln D_{j i}^{\mathrm{ER}}
$$

where $D_{j i}^{\mathrm{REF}}$ is the mutual diffusion coefficient at the reference state and is expressed as

$$
\ln D_{j i}^{\mathrm{REF}}=x_{j} \ln D_{i}^{0}+x_{i} \ln D_{j}^{0}
$$

$D_{j i}^{\mathrm{EX}}$ is the excess mutual diffusion coefficient. $D_{j i}^{\mathrm{EC}}$ is the combinatorial part of the excess mutual diffusion coefficient:

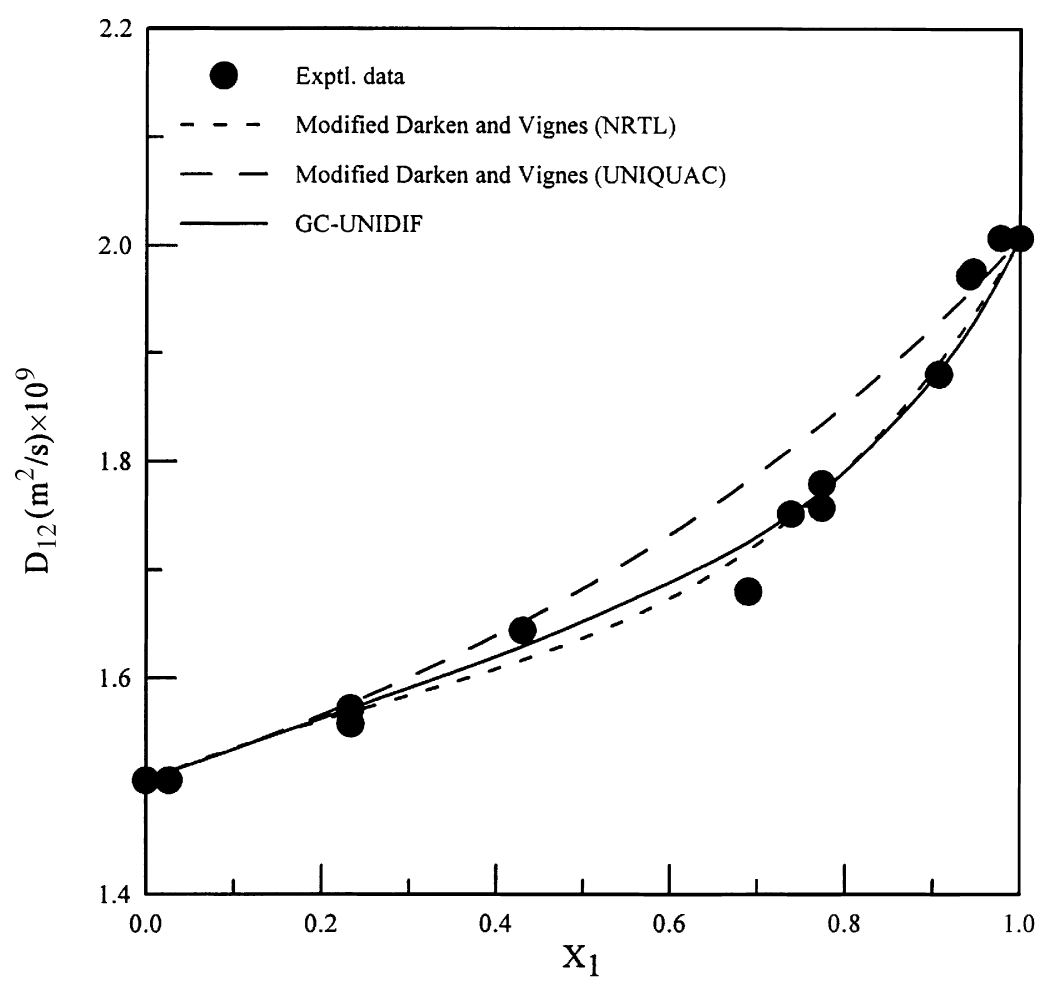

Fig. 2. Calculated results for the mutual diffusion coefficients of the binary mixture chloroform (1)+carbon tetrachloride (2) at 298 K. Data from [31]. 


$$
\begin{aligned}
\ln D_{j i}^{\mathrm{EC}}= & -2\left\{x_{j}\left[\left(\ln \frac{\phi_{i}}{x_{i}}-\frac{\phi_{i}}{x_{i}}+1\right)-x_{j}^{\left(i_{0}\right)}\left(\left.\ln \frac{\phi_{i}}{x_{i}}\right|_{x_{i} \rightarrow 0}-\left.\frac{\phi_{i}}{x_{i}}\right|_{x_{i} \rightarrow 0}+1\right)\right]\right. \\
& \left.+x_{i}\left[\left(\ln \frac{\phi_{j}}{x_{j}}-\frac{\phi_{j}}{x_{j}}+1\right)-x_{i}^{\left(j_{0}\right)}\left(\left.\ln \frac{\phi_{j}}{x_{j}}\right|_{x_{j} \rightarrow 0}-\left.\frac{\phi_{j}}{x_{j}}\right|_{x_{j} \rightarrow 0}+1\right)\right]\right\}
\end{aligned}
$$

and $D_{j i}^{\mathrm{ER}}$ is the residual part of the excess mutual diffusion coefficient:

$$
\begin{aligned}
\ln D_{j i}^{\mathrm{ER}}= & \frac{1}{T}\left\{x _ { j } q _ { i } \left[\sum_{k=1}^{n}\left(a_{k i} \theta_{k i}+\tau_{i k} \theta_{k k} \sum_{l=1}^{n} \theta_{l k}\left(a_{i k}-a_{l k}\right)\right)\right.\right. \\
& \left.-x_{j}^{\left(i_{0}\right)} \sum_{k=1}^{n}\left(a_{k i} \theta_{k i}^{\left(i_{0}\right)}+\tau_{i k} \theta_{k k}^{\left(i_{0}\right)} \sum_{l=1}^{n} \theta_{l k}^{\left(i_{0}\right)}\left(a_{i k}-a_{l k}\right)\right)\right] \\
& +x_{i} q_{j}\left[\sum_{k=1}^{n}\left(a_{k j} \theta_{k j}+\tau_{j k} \theta_{k k} \sum_{l=1}^{n} \theta_{l k}\left(a_{j k}-a_{l k}\right)\right)\right. \\
& \left.\left.-x_{i}^{\left(j_{0}\right)} \sum_{k=1}^{n}\left(a_{k j} \theta_{k j}^{\left(j_{0}\right)}+\tau_{j k} \theta_{k k}^{\left(j_{0}\right)} \sum_{l=1}^{n} \theta_{l k}^{\left(j_{0}\right)}\left(a_{j k}-a_{l k}\right)\right)\right]\right\}
\end{aligned}
$$

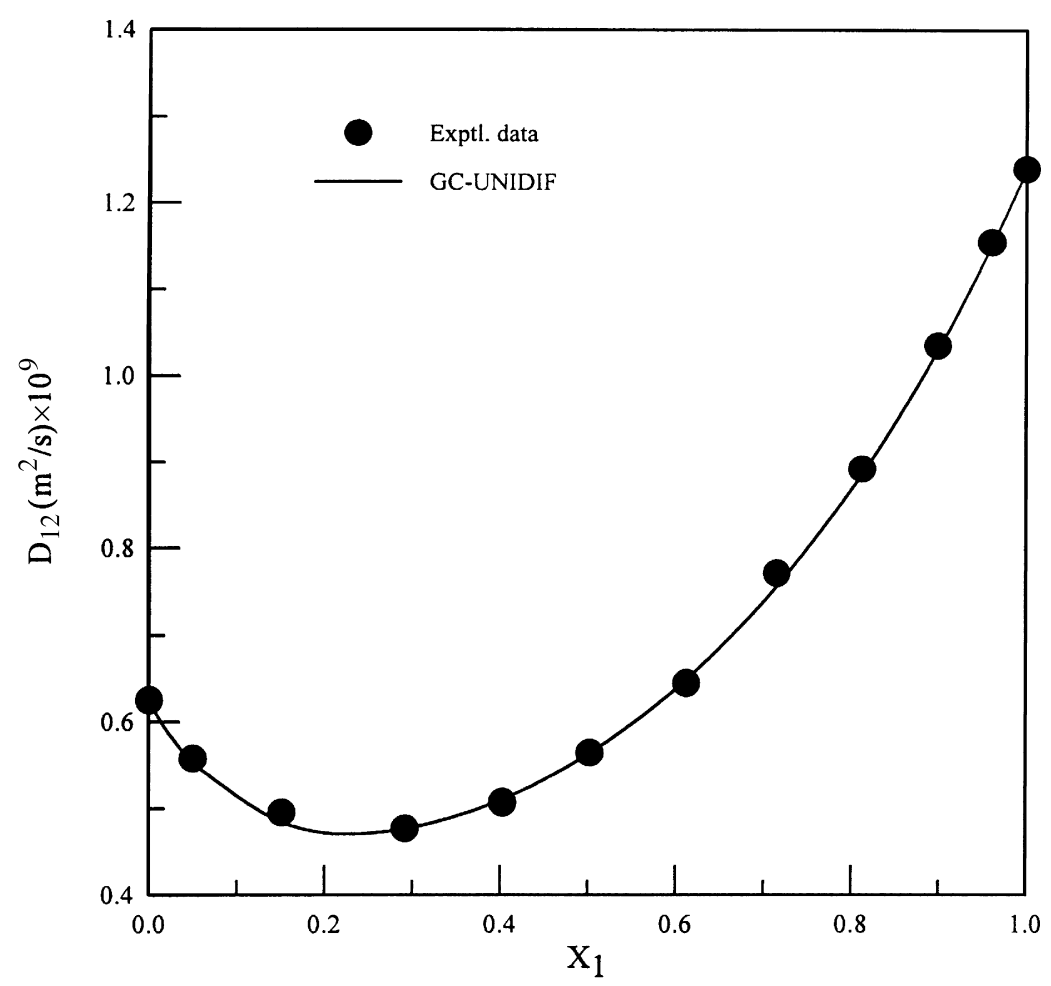

Fig. 3. Calculated results for the mutual diffusion coefficients of the binary mixture dimethylformamide (1)+water (2) at $278 \mathrm{~K}$. Data from [40]. 
Eq. (15) reduces to the UNIDIF equation [1] for a binary mixture. To apply this equation, the limiting diffusion coefficients are taken from either experimental data or from empirical correlation equations. The equilibrium distance parameter $\lambda_{i}$ is assumed to be proportional to the cubic root of either the molecular volume or volume parameter $r_{i}$ in the UNIQUAC model. The interaction parameters $a_{i j}$ are regressed from experimental data of the mutual diffusion coefficients.

The diffusion coefficient can not be calculated in a predictive way either by Eq. (15) or by the UNIDIF equation [1] in the absence of experimental data. A group contribution model can be developed in a similar way as the GC-UNIMOD model for predicting the viscosities. Following the idea of the UNIFAC and UNIDIF models, a group contribution method for the mutual diffusion coefficient is proposed in this study. The combinatorial part of the UNIDIF excess mutual diffusion coefficient is used directly. The solution of group concept is employed for the residual part of the excess mutual diffusion coefficient, and Eq. (18) is rewritten as

$$
\ln D_{j i}^{\mathrm{ER}}=\frac{1}{T}\left[x_{j} \sum_{\text {all group } m} v_{m}^{(i)}\left(\ln \Delta_{m}-\ln \Delta_{m}^{\left(i_{0}\right)}\right)+x_{i} \sum_{\text {all group } m} v_{m}^{(j)}\left(\ln \Delta_{m}-\ln \Delta_{m}^{\left(j_{0}\right)}\right)\right]
$$

where $v_{m}^{(i)}$ and $v_{m}^{(j)}$ are the numbers of group of type $m$ in molecule $i$ and $j$, respectively. $\ln \Delta_{m}-\ln \Delta_{m}^{\left(i_{0}\right)}$

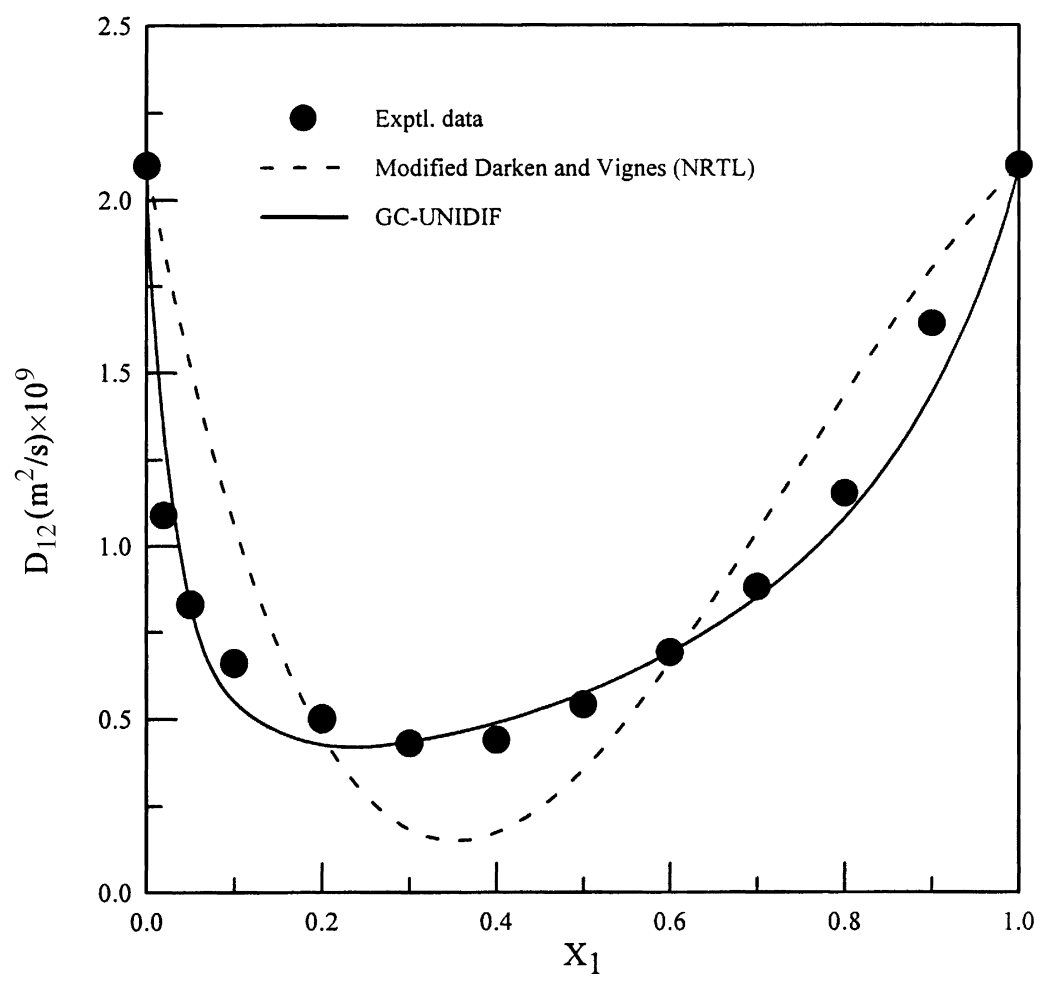

Fig. 4. Calculated results for the mutual diffusion coefficients of the binary mixture methanol (1)+carbon tetrachloride (2) at 293 K. Data from [29]. 
is defined as

$$
\begin{aligned}
\ln \Delta_{m}-\ln \Delta_{m}^{\left(i_{0}\right)}= & Q_{m}\left[\sum_{k=1}^{n}\left(a_{k m} \Theta_{k m}+\tau_{m k} \Theta_{k k} \sum_{l=1}^{n} \Theta_{l k}\left(a_{m k}-a_{l k}\right)\right)\right. \\
& \left.-x_{j}^{\left(i_{0}\right)} \sum_{k=1}^{n}\left(a_{k m} \Theta_{k m}^{\left(i_{0}\right)}+\tau_{m k} \Theta_{k k}^{\left(i_{0}\right)} \sum_{l=1}^{n} \Theta_{l k}^{\left(i_{0}\right)}\left(a_{m k}-a_{l k}\right)\right)\right]
\end{aligned}
$$

where $Q_{m}$ is the surface area parameter of group $m . \Theta_{k m}$ is expressed as

$$
\Theta_{k m}=\frac{X_{k} Q_{k} \tau_{k m}}{\sum_{l=1}^{n} X_{l} Q_{l} \tau_{l m}}
$$

Eq. (19) is employed in calculating the mutual diffusion coefficients of binary liquid mixtures. It is named as the group contribution UNIDIF (GC-UNIDIF) model. To apply the GC-UNIDIF equation, the limiting diffusion coefficients are taken from either experimental data or from empirical correlation equations. The equilibrium distance parameter $\lambda_{i}$ is assumed to be proportional to the cubic root of either the molecular volume or volume parameter $r_{i}$ in the UNIQUAC model. The interaction parameters $a_{i j}$ are regressed from experimental data of binary mutual diffusion coefficients and expressed in a generalized form.

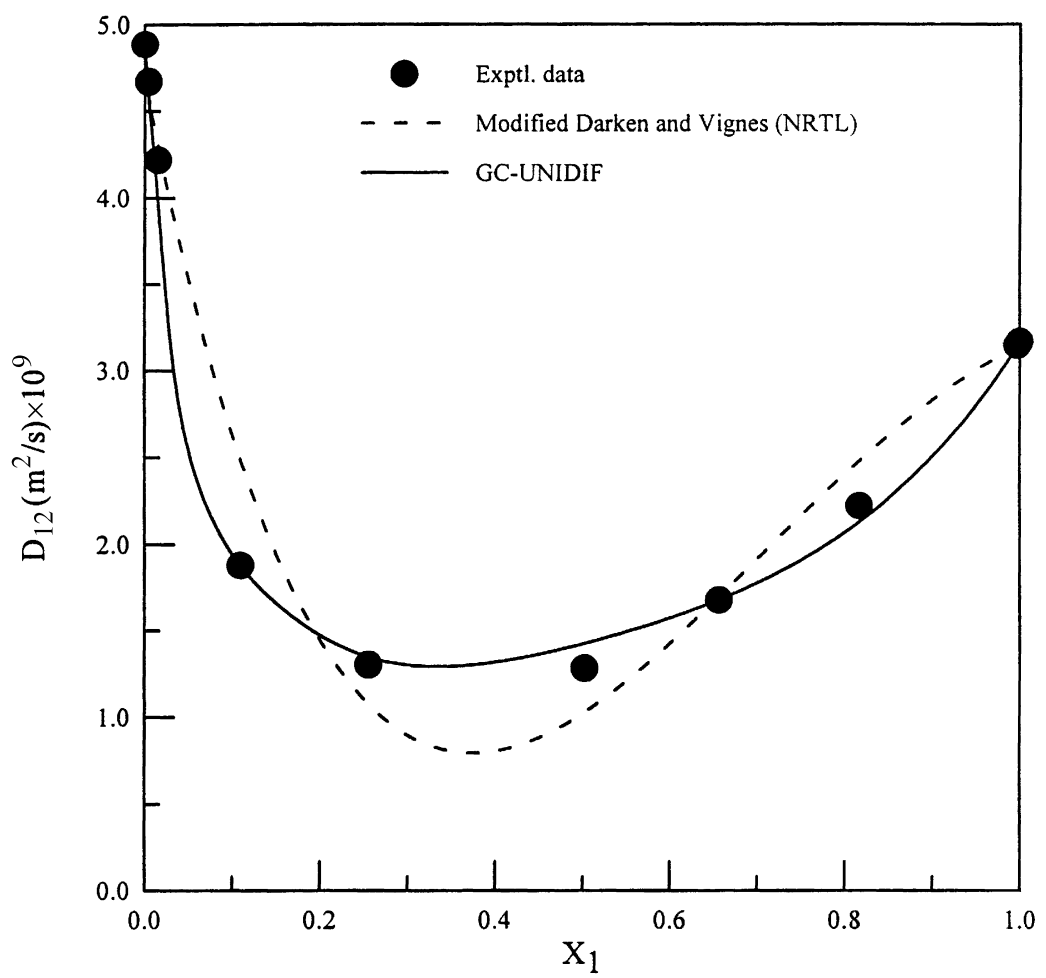

Fig. 5. Calculated results for the mutual diffusion coefficients of the binary mixture methanol (1)+benzene (2) at $313 \mathrm{~K}$. Data from [32]. 
The GC-UNIDIF model is compared with two types of correlative equations of the modified Darken and Vignes models. The modified Darken equation expresses the mutual diffusion coefficient by

$$
D_{12}=\left(x_{1} D_{2}^{0}+x_{2} D_{1}^{0}\right) \times \frac{\mathrm{d} \ln a_{1}}{\operatorname{dln} x_{1}}
$$

where $a$ is the activity which is calculated from either the NRTL or the UNIQUAC activity coefficient model. The Vignes equation expresses the mutual diffusion equation by

$$
D_{12}=\left(D_{2}^{0}\right)^{x_{1}}\left(D_{1}^{0}\right)^{x_{2}} \times \frac{\mathrm{d} \ln a_{1}}{\operatorname{dln} x_{1}}
$$

The binary parameters in the NRTL or the UNIQUAC model are regressed from the experimental data of vapor-liquid equilibrium or the experimental data of the mutual diffusion coefficients.

\section{Results and discussion}

In the GC-UNIDIF method, the mutual diffusion coefficient of a binary liquid mixture is contributed by all functional groups comprised of the components. The group interaction parameters for this method are listed in Table 1.

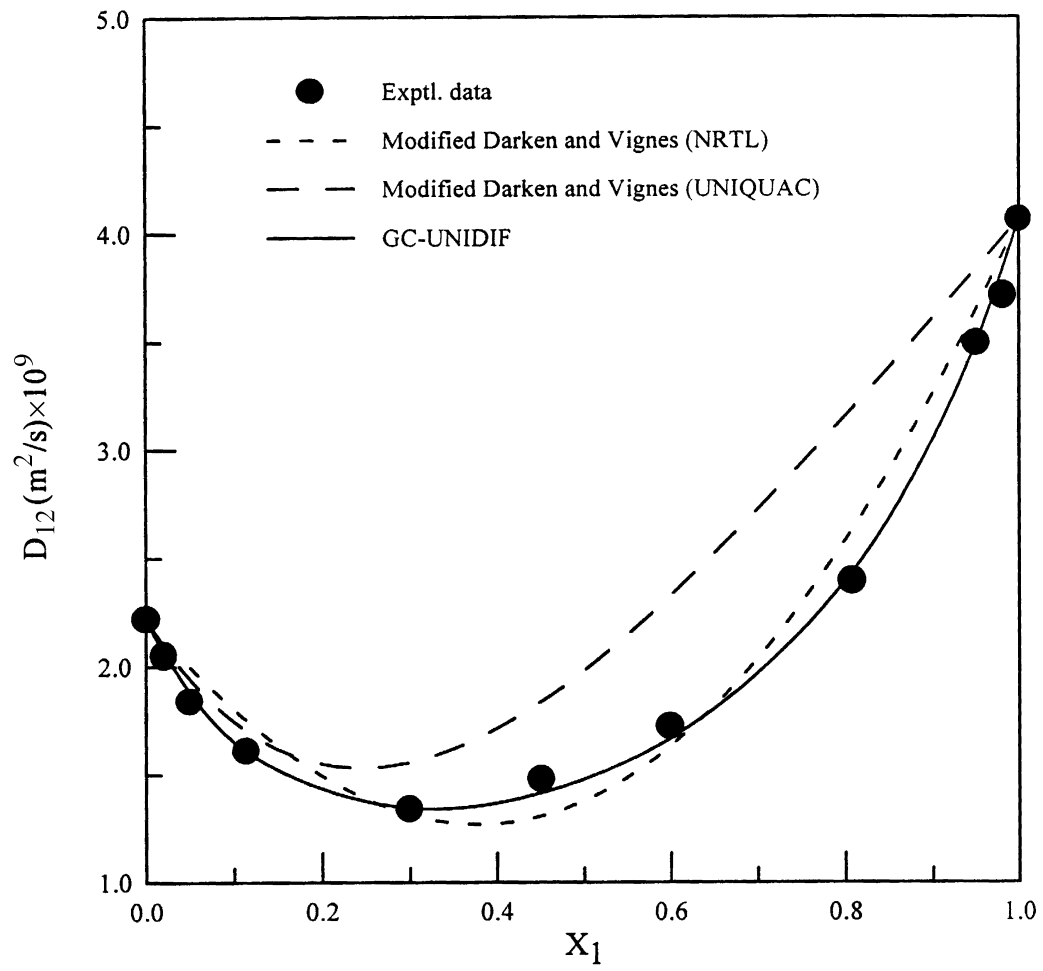

Fig. 6. Calculated results for the mutual diffusion coefficients of the binary mixture acetone (1)+cyclohexane (2) at 298 K. Data from [33]. 
For the liquid mixtures of alkanes, the residual part of the mutual diffusion coefficient in the GC-UNIDIF model vanishes and the model is reduced to the UNIDIF model [1] without any group interaction parameter. For other binary mixtures, various types of functional groups are defined in the same way as the UNIFAC model. The corresponding group volume and surface area parameters are taken from literature [15]. The classified results are summarized as follows:

1. Liquid mixtures containing the functional group pair of $\mathrm{CH}_{2}-\mathrm{CCl}_{4}$ : 66 data points of the mutual diffusion coefficients for nine liquid mixtures in the temperature range from 298.15 to $308.15 \mathrm{~K}$ were used to obtain the group interaction parameters. The absolute average deviation (AAD) for nine systems is $1.5 \%$. Fig. 1 shows the calculated results for the mutual diffusion coefficients of $n$-alkane+carbon tetrachloride binary mixtures. Only two group interaction parameters are used for various alkane systems and the agreement with the experimental data is satisfactory.

2. Liquid mixtures containing the functional group pair of $\mathrm{CH}_{2}-\mathrm{CHCl}_{3}: 36$ data points of the mutual diffusion coefficients for six liquid mixtures at the temperature of $303.15 \mathrm{~K}$ were used. The AAD for these six systems is $1.9 \%$.

3. Liquid mixtures containing the functional group pair of $\mathrm{CHCl}_{3}-\mathrm{CCl}_{4}: 12$ data points of the mutual diffusion coefficients for the liquid mixture at $298.15 \mathrm{~K}$ were used. The AAD for this system is $1.1 \%$. Fig. 2 shows the comparison of the calculated results of the mutual diffusion coefficients of carbon tetrachloride+chloroform binary mixtures. The GC-UNIDIF method gives good agreement with

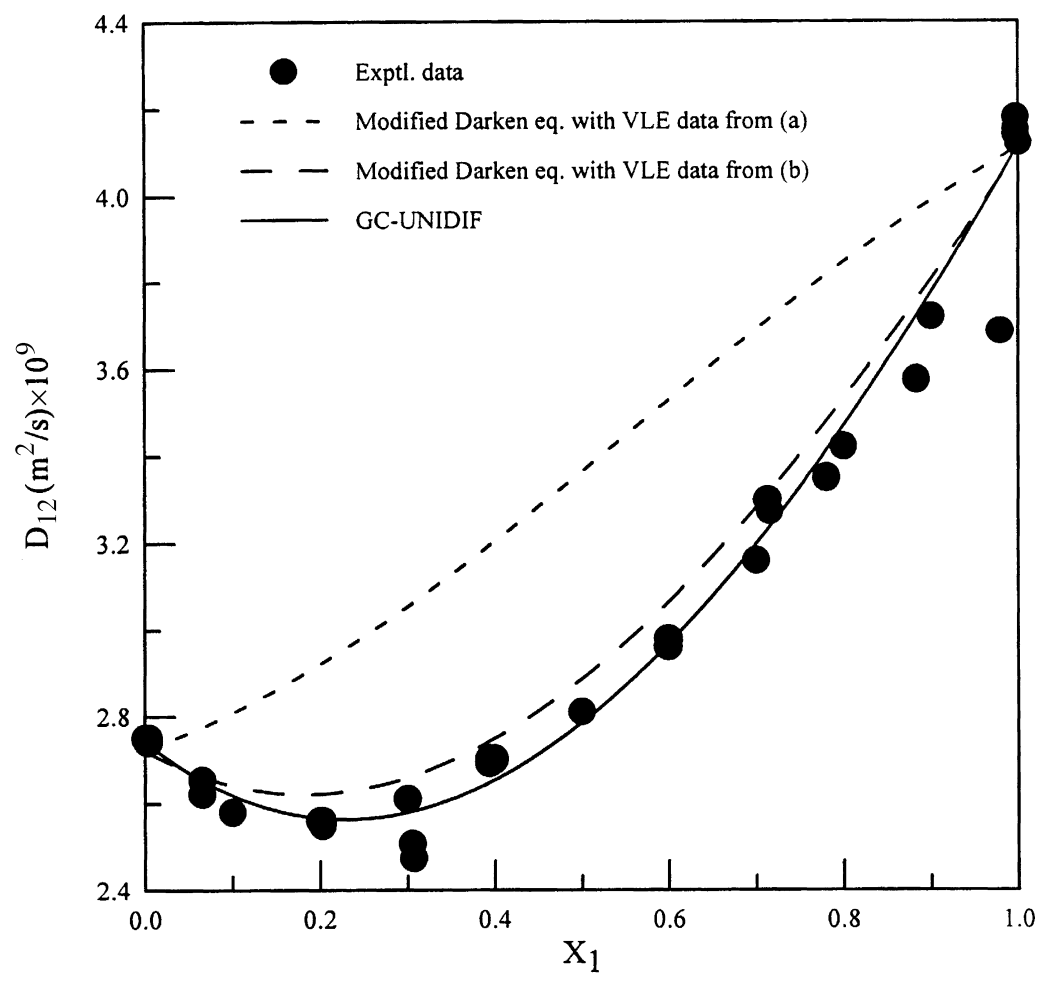

Fig. 7. Comparison of the calculated results for the mutual diffusion coefficients of the binary mixture acetone (1)+benzene (2) at 298 K. Data from [6,26,35]. In the modified Darken equation, VLE data are taken from either (a) [26], or (b) [6]. 
experimental data. The modified Darken model and Vignes model yields satisfactory results with the thermodynamic factor regressed by the experimental diffusion coefficient data and the NRTL model. Larger deviation occurs, however, if the thermodynamic factor is regressed by the UNIQUAC model.

4. Liquid mixtures containing the functional group pair of dimethylformamide (DMF)- $\mathrm{H}_{2} \mathrm{O}$ : 10 data points of the mutual diffusion coefficients were tested for the liquid mixture at $278.15 \mathrm{~K}$. The AAD for this system is $0.8 \%$. Fig. 3 shows the comparison of the calculated mutual diffusion coefficients of $\mathrm{DMF}+$ water. In this highly non-ideal aqueous system, satisfactory results are obtained by employing the GC-UNIDIF model.

5. Liquid mixtures containing the functional group pair of $n$-methylpyrrolidone (NMP)- $\mathrm{H}_{2} \mathrm{O}$ : 10 data points of the mutual diffusion coefficients were used for the liquid mixture at $278.15 \mathrm{~K}$. The GCUNIDIF model yields satisfactory results with an AAD of about $3.4 \%$.

6. Liquid mixtures containing the functional group pair of $\mathrm{CH}_{3} \mathrm{OH}-\mathrm{CCl}_{4}: 11$ data points of the mutual diffusion coefficients for the liquid mixture at $293.15 \mathrm{~K}$ were examined. The AAD for this system is 8.3\%. Fig. 4 shows the calculated results of the mutual diffusion coefficients of methanol+carbon tetrachloride. For this highly non-ideal system, it is demonstrated that the GC-UNIDIF model gives good agreement with the experimental data. The modified Darken model and Vignes model, with the thermodynamic factor regressed using experimental diffusion coefficient data and the NRTL model, give larger calculation errors.

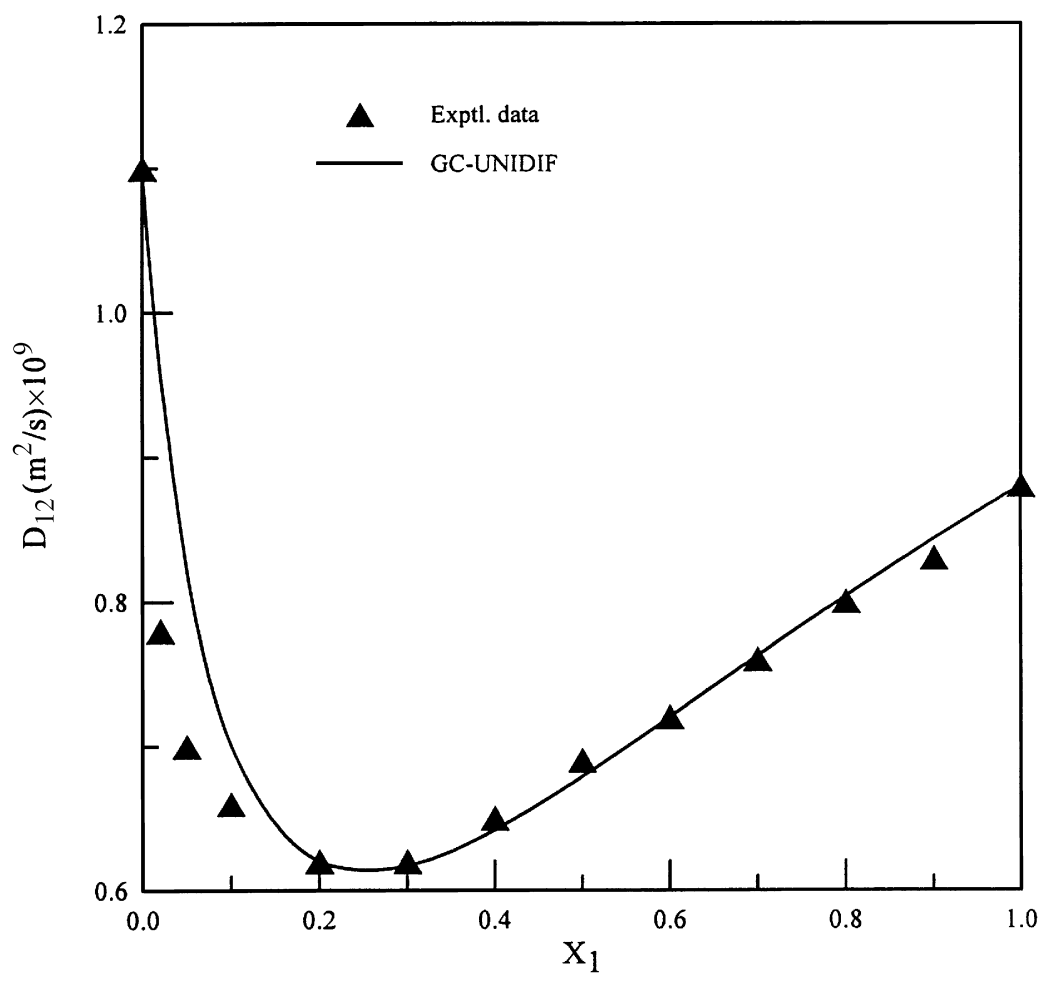

Fig. 8. Calculated results for the mutual diffusion coefficients of the binary mixture $n$-propanol (1)+carbon tetrachloride (2) at 293 K. Data from [29]. 
7. Liquid mixtures containing the functional group pair of $\mathrm{CH}_{3} \mathrm{OH}-\mathrm{ACH}$ : eight data points of the mutual diffusion coefficients were used for the liquid mixture at $313.15 \mathrm{~K}$. The AAD for this system is $3.5 \%$. Fig. 5 shows the calculated results of the mutual diffusion coefficients of methanol+benzene. The modified Darken and Vignes equations with thermodynamic factors regressed from experimental diffusion coefficient data show appreciable deviations. For this highly non-ideal system, it is again demonstrated that the GC-UNIDIF model gives good agreement with the experimental data.

8. Liquid mixtures containing the functional group pair of $\mathrm{CH}_{3} \mathrm{OH}-\mathrm{H}_{2} \mathrm{O}: 25$ data points of the mutual diffusion coefficients were tested for the liquid mixture at $278.15-313.13 \mathrm{~K}$. The AAD for this system is $3.0 \%$. The GC-UNIDIF model predicts good results within a temperature range of $35^{\circ} \mathrm{C}$.

9. Liquid mixtures containing the functional group pair of aromatic $\mathrm{ACH}-\mathrm{CH}_{2}: 114$ data points of the mutual diffusion coefficients for three liquid mixtures at $293.15-358.15 \mathrm{~K}$ were examined. The AAD for three systems is $2.2 \%$.

10. Liquid mixtures containing the functional group pair of $\mathrm{CH}_{2} \mathrm{CO}-\mathrm{CH}_{2}$ : nine data points of the mutual diffusion coefficients for the liquid mixture at $298.15 \mathrm{~K}$ were tested. The AAD for this data set is 1.8\%. Fig. 6 shows the comparison of the calculated results of the mutual diffusion coefficients of acetone+cyclohexane from various models. The GC-UNIDIF model gives satisfactory results. The modified Darken and Vignes models with the thermodynamic factor fitted by the experimental diffusion coefficient data and the NRTL model yield comparable results. Larger errors appear with the thermodynamic factor fitted by the UNIQUAC model.

11. Liquid mixtures containing the functional group pair of $\mathrm{CH}_{2}-\mathrm{OH}$ : 56 data points of the mutual diffusion coefficients for 14 liquid mixtures at $298.15 \mathrm{~K}$ were used in the generalized regression. The $\mathrm{AAD}$ for these systems is $12.3 \%$.

12. Liquid mixtures containing the functional group pair of $\mathrm{COO}-\mathrm{CH}_{2}$ : nine data points of the mutual diffusion coefficients for the liquid mixture at $293.15 \mathrm{~K}$ were used. The AAD for this system is $13.4 \%$.

13. Liquid mixtures containing the functional group pair of $\mathrm{ACCH}_{2}-\mathrm{ACH}: 18$ data points of the mutual diffusion coefficients were examined for the liquid mixture at 293.15-313.15 K. The AAD for this system is $0.6 \%$.

14. Liquid mixtures containing the functional group pair of $\mathrm{CHCl}_{3}-\mathrm{ACH}: 27$ data points of the mutual diffusion coefficients for the liquid mixture at $298.15-328.15 \mathrm{~K}$ were tested. The AAD for this data set is $0.5 \%$.

15. Liquid mixtures containing the functional groups $\mathrm{CH}_{2} \mathrm{CO}, \mathrm{CH}_{2}$, and $\mathrm{CCl}_{4}$ which consist of the three pairs of $\mathrm{CH}_{2} \mathrm{CO}-\mathrm{CH}_{2}, \mathrm{CH}_{2} \mathrm{CO}-\mathrm{CCl}_{4}$, and $\mathrm{CH}_{2}-\mathrm{CCl}_{4}$ : the interaction parameters for the pairs of $\mathrm{CH}_{2} \mathrm{CO}-\mathrm{CH}_{2}$ and $\mathrm{CH}_{2}-\mathrm{CCl}_{4}$ are obtained from the previous regression. Only the pair of $\mathrm{CH}_{2} \mathrm{CO}-\mathrm{CCl} 4$ needs to be fitted. Nineteen data points of the mutual diffusion coefficients for two liquid mixtures at $298.15 \mathrm{~K}$ were examined. The AAD for these two systems is $2.8 \%$.

16. Liquid mixtures containing the functional groups $\mathrm{CH}_{2} \mathrm{CO}, \mathrm{CH}_{2}$, and $\mathrm{ACH}$ which include three pairs of $\mathrm{CH}_{2} \mathrm{CO}-\mathrm{CH}_{2}, \mathrm{ACH}-\mathrm{CH}_{2}$, and $\mathrm{CH}_{2} \mathrm{CO}-\mathrm{ACH}$ : the interaction parameters for the pairs of $\mathrm{CH}_{2} \mathrm{CO}-\mathrm{CH}_{2}$ and $\mathrm{ACH}-\mathrm{CH}_{2}$ are obtained from the previous results. Only the pair of $\mathrm{CH}_{2} \mathrm{CO}-\mathrm{ACH}$ needs to be determined. Thirty-one data points of the mutual diffusion coefficients for the liquid mixture at $298.15 \mathrm{~K}$ were tested. The AAD for this system is $1.5 \%$. Fig. 7 shows the calculated results of the mutual diffusion coefficients of acetone+benzene from various models. The GC-UNIDIF model gives good agreement with the experimental data. The modified Darken or Vignes equations with thermodynamic factors regressed from diffusion coefficient data yield comparably good 
Table 2

Comparison of the calculated results for the mutual diffusion coefficients of binary mixture from various correlation methods

\begin{tabular}{|c|c|c|c|c|c|c|c|c|}
\hline \multirow[t]{3}{*}{ System } & \multirow{3}{*}{$\begin{array}{l}\text { Data } \\
\text { points }\end{array}$} & \multirow{3}{*}{$\begin{array}{l}\text { Temperature } \\
\text { range }(K)\end{array}$} & \multicolumn{5}{|c|}{$\operatorname{AAD}(\%)^{\mathrm{a}}$} & \multirow[t]{3}{*}{ References } \\
\hline & & & \multicolumn{2}{|c|}{$\begin{array}{l}\text { Modified } \\
\text { Darken }\end{array}$} & \multicolumn{2}{|l|}{ Vignes } & \multirow[t]{2}{*}{ This work } & \\
\hline & & & NRTL & $\begin{array}{l}\text { UNI- } \\
\text { QUAC }\end{array}$ & NRTL & $\begin{array}{l}\text { UNI- } \\
\text { QUAC }\end{array}$ & & \\
\hline \multicolumn{9}{|l|}{ Non-polar+non-polar } \\
\hline $\begin{array}{l}\text { 3-Methylpentane }+ \\
\text { carbon tetrachloride }\end{array}$ & 6 & 303.15 & 0.7 & 2.7 & 1.2 & 1.3 & 0.9 & {$[16]$} \\
\hline \multirow[t]{2}{*}{$\begin{array}{l}\text { 2,3-Dimethylpentane+ } \\
\text { carbon tetrachloride }\end{array}$} & 6 & 303.15 & 0.3 & 3.1 & 0.3 & 1.3 & 1.9 & {$[17]$} \\
\hline & 6 & 303.15 & 0.4 & 2.5 & 1.6 & 1.0 & 1.2 & {$[17]$} \\
\hline \multicolumn{9}{|l|}{$\begin{array}{r}\text { 2,2,4-Trimethylpentane+ } \\
\text { carbon tetrachloride }\end{array}$} \\
\hline$n$-Hexane+carbon tetrachloride & 12 & $298.15-303.15$ & 0.7 & 1.7 & 1.0 & 1.0 & 1.0 & {$[18]$} \\
\hline$n$-Heptane+carbon tetrachloride & 6 & 303.15 & 0.7 & 1.5 & 0.9 & 0.7 & 1.3 & {$[18]$} \\
\hline$n$-Octane+carbon tetrachloride & 6 & 303.15 & 2.5 & 1.4 & 2.3 & 3.2 & 2.7 & {$[17]$} \\
\hline$n$-Decane + carbon tetrachloride & 4 & 298.15 & 0.4 & 1.9 & 0.3 & 1.3 & 3.0 & {$[17,19]$} \\
\hline$n$-Dodecane+carbon tetrachloride & 4 & 298.15 & 0.5 & 5.1 & 0.5 & 4.7 & 1.8 & {$[17]$} \\
\hline Cyclohexane + carbon tetrachloride & 16 & $298.15-308.15$ & 0.2 & 0.2 & 0.2 & 0.2 & 1.1 & {$[20,21]$} \\
\hline Benzene $+n$-hexane & 11 & 298.15 & 0.4 & 3.5 & 0.3 & 2.1 & 3.7 & {$[22,23]$} \\
\hline Benzene $+n$-heptane & 34 & $293.15-358.15$ & 4.8 & 3.8 & 4.5 & 3.7 & 4.5 & [23] \\
\hline Benzene+cyclohexane & 69 & $293.15-333.15$ & 1.2 & 2.1 & 1.2 & 2.1 & 0.9 & [24-27] \\
\hline Toluene+cyclohexane & 27 & $298.15-328.15$ & 1.4 & 1.6 & 1.4 & 1.3 & 0.9 & {$[28]$} \\
\hline Toluene+benzene & 18 & $293.15-313.15$ & 0.3 & 1.0 & 0.3 & 0.8 & 0.6 & {$[28]$} \\
\hline \multicolumn{9}{|l|}{ Non-polar+polar } \\
\hline Ethanol+carbon tetrachloride & 9 & 298.15 & 1.8 & 13 & 1.8 & 12.7 & 13.7 & [29] \\
\hline$n$-Propanol+carbon tetrachloride & 11 & 293.15 & 12.2 & 11.6 & 12.1 & 11.4 & 4.8 & {$[30]$} \\
\hline$n$-Butanol+carbon tetrachloride & 11 & 293.15 & 7.9 & 6.6 & 7.9 & 6.6 & 10.1 & {$[30]$} \\
\hline Ethanol+benzene & 27 & $298.15-313.13$ & 14.4 & 7.8 & 14.2 & 7.9 & 4.5 & {$[31]$} \\
\hline Chloroform + carbon tetrachloride & 12 & 298.15 & 1.1 & 2.1 & 1.1 & 1.9 & 1.1 & {$[32]$} \\
\hline$n$-Hexane+chloroform & 6 & 303.15 & 1.1 & 5 & 1.1 & 4 & 2.0 & [16] \\
\hline$n$-Heptane+chloroform & 6 & 303.15 & 0.7 & 3.6 & 0.7 & 3.1 & 2.3 & {$[16]$} \\
\hline$n$-Octane+chloroform & 6 & 303.15 & 0.5 & 4.7 & 0.5 & 4.2 & 1.8 & [16] \\
\hline 3-Methylpentane+chloroform & 6 & 303.15 & 0.7 & 5.7 & 0.7 & 4.5 & 2.9 & {$[16]$} \\
\hline 2,3-Dimethylpentane+chloroform & 6 & 303.15 & 1.1 & 4.1 & 1.1 & 3.3 & 1.2 & {$[16]$} \\
\hline 2,2,4-Trimethylpentane+chloroform & 6 & 303.15 & 0.4 & 5.8 & 0.4 & 5.2 & 0.9 & {$[16]$} \\
\hline Methanol+carbon tetrachloride & 11 & 293.15 & 39.4 & 49 & 39.4 & 49 & 8.3 & {$[30]$} \\
\hline Methanol+benzene & 8 & 313.15 & 10.9 & 15.9 & 10.6 & 15.5 & 3.5 & {$[33]$} \\
\hline Acetone+cyclohexane & 9 & 298.15 & 6.7 & 15.5 & 6.2 & 14.4 & 1.8 & {$[34]$} \\
\hline Cyclohexane+ethanol & 4 & 298.15 & 1.7 & 13.8 & 0.9 & 10.4 & 12.7 & {$[35]$} \\
\hline Cyclohexane $+n$-propanol & 4 & 298.15 & 1.0 & 13.4 & 0.3 & 10.2 & 14.6 & {$[35]$} \\
\hline Cyclohexane $+n$-butanol & 4 & 298.15 & 0.8 & 16.0 & 0.4 & 12.3 & 18.4 & {$[35]$} \\
\hline Cyclohexane $+n$-pentanol & 4 & 298.15 & 1.6 & 16.7 & 0.8 & 12.1 & 17.0 & {$[35]$} \\
\hline Cyclohexane $+n$-hexanol & 4 & 298.15 & 0.9 & 18.7 & 0.2 & 14.7 & 18.8 & [35] \\
\hline Cyclohexane $+n$-heptanol & 4 & 298.15 & 0.8 & 21.4 & 0.1 & 16.4 & 18.1 & {$[35]$} \\
\hline Cyclohexane $+n$-octanol & 4 & 298.15 & 0.4 & 18.0 & 0.5 & 14.0 & 14.9 & {$[35]$} \\
\hline Methylcyclohexane+ethanol & 4 & 298.15 & 0.5 & 5.4 & 0.5 & 5.4 & 17.4 & {$[35]$} \\
\hline Methylcyclohexane $+n$-propanol & 4 & 298.15 & 2.8 & 8.5 & 2.8 & 8.5 & 6.7 & {$[35]$} \\
\hline
\end{tabular}


Table 2 (Continued)

\begin{tabular}{|c|c|c|c|c|c|c|c|c|}
\hline \multirow[t]{3}{*}{ System } & \multirow{3}{*}{$\begin{array}{l}\text { Data } \\
\text { points }\end{array}$} & \multirow{3}{*}{$\begin{array}{l}\text { Temperature } \\
\text { range }(\mathrm{K})\end{array}$} & \multicolumn{5}{|c|}{$\operatorname{AAD}(\%)^{\mathrm{a}}$} & \multirow[t]{3}{*}{ References } \\
\hline & & & \multicolumn{2}{|c|}{$\begin{array}{l}\text { Modified } \\
\text { Darken }\end{array}$} & \multicolumn{2}{|l|}{ Vignes } & \multirow[t]{2}{*}{ This work } & \\
\hline & & & NRTL & $\begin{array}{l}\text { UNI- } \\
\text { QUAC }\end{array}$ & NRTL & $\begin{array}{l}\text { UNI- } \\
\text { QUAC }\end{array}$ & & \\
\hline Methylcyclohexane $+n$-butanol & 4 & 298.15 & 4.1 & 13.3 & 4.1 & 12.9 & 4.8 & {$[35]$} \\
\hline Methylcyclohexane $+n$-pentanol & 4 & 298.15 & 3.8 & 10.8 & 3.7 & 9.3 & 5.0 & {$[35]$} \\
\hline Methylcyclohexane $+n$-hexanol & 4 & 298.15 & 4.9 & 12.1 & 4.7 & 10.2 & 6.2 & {$[35]$} \\
\hline Methylcyclohexane $+n$-heptanol & 4 & 298.15 & 5.7 & 16.2 & 5.4 & 13.6 & 4.9 & {$[35]$} \\
\hline Methylcyclohexane $+n$-octanol & 4 & 298.15 & 1.8 & 8.5 & 1.7 & 5.9 & 10.1 & {$[35]$} \\
\hline Ethyl acetate+cyclohexane & 9 & 293.15 & 0.1 & 20.8 & 0.0 & 20.2 & 13.4 & {$[24]$} \\
\hline Chloroform+benzene & 27 & $298.15-328.15$ & 0.8 & 0.7 & 0.8 & 0.7 & 0.5 & {$[28]$} \\
\hline Acetone + carbon tetrachloride & 12 & 298.15 & 4.4 & 6.5 & 4.2 & 6 & 2.2 & {$[31,36]$} \\
\hline $\begin{array}{l}\text { Methyl ethyl ketone+ } \\
\text { carbon tetrachloride }\end{array}$ & 7 & 298.15 & 1.9 & 3.5 & 1.8 & 2.6 & 3.8 & [29] \\
\hline Acetone+benzene & 31 & 298.15 & 1.7 & 2.2 & 1.7 & 1.9 & 1.5 & {$[6,27,36]$} \\
\hline \multicolumn{9}{|l|}{ Polar+polar } \\
\hline Acetone+chloroform & 43 & $298.15-328.15$ & 2.1 & 1.9 & 2.1 & 2.1 & 2.3 & {$[27,31,37,38]$} \\
\hline Methanol+water & 25 & $278.15-313.13$ & 9 & 3.8 & 8.5 & 3.4 & 3.0 & {$[39,40]$} \\
\hline Dimethylformamide+water & 10 & 278.15 & 2.0 & 26.9 & 1.7 & 10.4 & 0.8 & [41] \\
\hline$n$-Methylpyrrolidone+water & 10 & 278.15 & 8.2 & 34.8 & 8.1 & 26.6 & 3.4 & [41] \\
\hline Grand average & 589 & & 3.8 & 6.7 & 3.8 & 5.8 & 3.6 & \\
\hline
\end{tabular}

${ }^{\mathrm{a}} \mathrm{AAD}(\%)=(100 / n) \sum_{i=1}^{n}\left|\left(D_{12, i}^{\mathrm{cal}}-D_{12, i}^{\exp }\right) / D_{12, i}^{\exp }\right|$.

results. The modified Darken model using the thermodynamic factor determined from different vapor-liquid equilibrium data are also shown in Fig. 7. It is obvious that the thermodynamic factors evaluated by different experimental data have very significant effect on the calculation of the diffusion coefficients.

17. Liquid mixtures containing the functional groups $\mathrm{CH}_{2} \mathrm{CO}, \mathrm{CHCl}_{3}$, and $\mathrm{CH}_{2}$ which include three pairs of $\mathrm{CH}_{2} \mathrm{CO}-\mathrm{CH}_{2}, \mathrm{CHCl}_{3}-\mathrm{CH}_{2}$, and $\mathrm{CH}_{2} \mathrm{CO}-\mathrm{CHCl}_{3}$ : the group interaction parameters for the pairs of $\mathrm{CH}_{2} \mathrm{CO}-\mathrm{CH}_{2}$ and $\mathrm{CHCl}_{3}-\mathrm{CH}_{2}$ are calculated from the previous regression. Only the pair of $\mathrm{CH}_{2} \mathrm{CO}-\mathrm{CHCl}_{3}$ needs to be evaluated. In total, 43 data points of the mutual diffusion coefficients for the liquid mixture at $298.15-328.15 \mathrm{~K}$ were examined. The AAD for this system is $2.3 \%$.

18. Liquid mixtures containing the functional groups $\mathrm{OH}, \mathrm{CH}_{2}$, and $\mathrm{CCl}_{4}$ which include three pairs of $\mathrm{OH}-\mathrm{CH}_{2}, \mathrm{CH}_{2}-\mathrm{CCl}_{4}$, and $\mathrm{OH}-\mathrm{CCl}_{4}$ : the interaction parameters for the pairs of $\mathrm{OH}-\mathrm{CH}_{2}$ and $\mathrm{CH}_{2}-\mathrm{CCl}_{4}$ are calculated from the previous regression. Only the pair of $\mathrm{OH}-\mathrm{CCl}_{4}$ needs to be regressed. Thirty-one data points of the mutual diffusion coefficients for nine liquid mixtures at $293.15-298.15 \mathrm{~K}$ are tested. The AAD for three systems is $9.3 \%$. For the highly non-ideal system of $n$-propanol+carbon tetrachloride as shown in Fig. 8, satisfactory results are obtained from the GC-UNIDIF model.

19. Liquid mixtures containing the functional groups $\mathrm{OH}, \mathrm{CH}_{2}$, and $\mathrm{ACH}$ which include three pairs of $\mathrm{OH}-\mathrm{CH}_{2}, \mathrm{CH}_{2}-\mathrm{ACH}$, and $\mathrm{OH}-\mathrm{ACH}$ : the interaction parameters for the pairs of $\mathrm{OH}-\mathrm{CH}_{2}$ and 
Table 3

Group interaction parameters

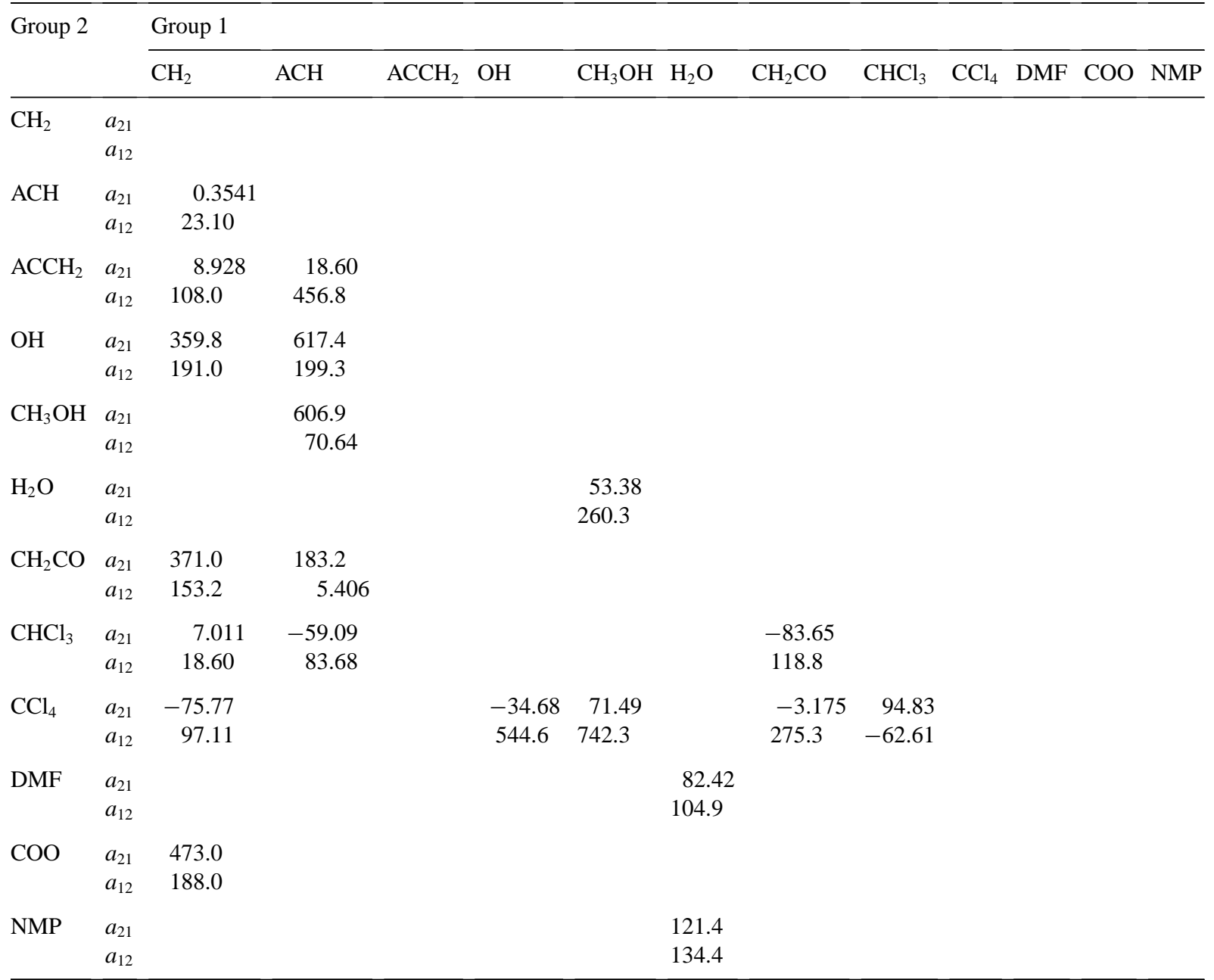

$\mathrm{CH}_{2}-\mathrm{ACH}$ are calculated from the previous regression. Only the pair of $\mathrm{OH}-\mathrm{ACH}$ needs to be regressed. Twenty-seven data points of the mutual diffusion coefficients for the liquid mixture at $298.15-313.13 \mathrm{~K}$ are evaluated. The AAD for this system is $4.5 \%$.

20. Liquid mixtures containing the functional groups $\mathrm{ACCH}_{2}, \mathrm{CH}_{2}$, and $\mathrm{ACH}$ which include three pairs of $\mathrm{ACCH}_{2}-\mathrm{CH}_{2}, \mathrm{CH}_{2}-\mathrm{ACH}$, and $\mathrm{ACCH}_{2}-\mathrm{ACH}$ : the interaction parameters for the pairs of $\mathrm{ACCH}_{2}-\mathrm{ACH}$ and $\mathrm{CH}_{2}-\mathrm{ACH}$ are calculated from the previous regression. The interaction parameters for the pair of $\mathrm{ACCH}_{2}-\mathrm{CH}_{2}$ are regressed from 27 data points of the mutual diffusion coefficients for the liquid mixture at $298.15-328.15 \mathrm{~K}$. The AAD for this system is $0.9 \%$.

Although thermodynamic factors are usually employed in calculating the diffusion coefficients, there are appreciable different results when various activity coefficient models are used. It is not always appropriate to apply the optimal binary parameters from VLE calculations to determine the diffusion coefficients. 
Table 4

Calculated results of the GC-UNIDIF method using regressed parameters for mutual diffusion coefficients of liquid binary mixtures

\begin{tabular}{llcllrl}
\hline Item & System & Points & Temperature range $(\mathrm{K})$ & Error $\left(10^{-9} \mathrm{~m}^{2} / \mathrm{s}\right)^{\mathrm{a}}$ & AAD $(\%)^{\mathrm{b}}$ & References \\
\hline 1 & Isobutanol+ $n$-propanol & 19 & 303.15 & 0.005 & 1.0 & {$[42]$} \\
2 & Toluene+ $n$-hexane & 9 & 298.15 & 0.144 & 5.1 & {$[43]$} \\
3 & Benzene+ethanol & 4 & 301.15 & 0.152 & 12.9 & {$[44]$} \\
4 & Benzene+ $n$-propanol & 4 & 301.15 & 0.142 & 12.4 & {$[44]$} \\
5 & Benzene+ $n$-butanol & 4 & 301.15 & 0.163 & 14.6 & {$[44]$} \\
6 & Benzene+ $n$-pentanol & 4 & 301.15 & 0.177 & 17.9 & {$[44]$} \\
\hline
\end{tabular}

${ }^{\mathrm{a}}$ Error $=(1 / n) \sum_{i=1}^{n}\left|D_{12, i}^{\mathrm{cal}}-D_{12, i}^{\mathrm{exp}}\right|$.

${ }^{\mathrm{b}} \operatorname{AAD}(\%)=(100 / n) \sum_{i=1}^{n}\left|\left(D_{12, i}^{\mathrm{cal}}-D_{12, i}^{\exp }\right) / D_{12, i}^{\exp }\right|$.

Comparison of the calculated results from the GC-UNIDIF model with those from the correlative methods of the modified Darken and Vignes equations are presented in Table 2. In these correlative methods, the thermodynamic factors are regressed using the experimental diffusion coefficient data. The GC-UNIDIF model yields a generalized calculation result. The GC-UNIDIF model gives comparably good accuracy to those correlative methods with optimally fitted binary parameters. The grand AAD of the GC-UNIDIF

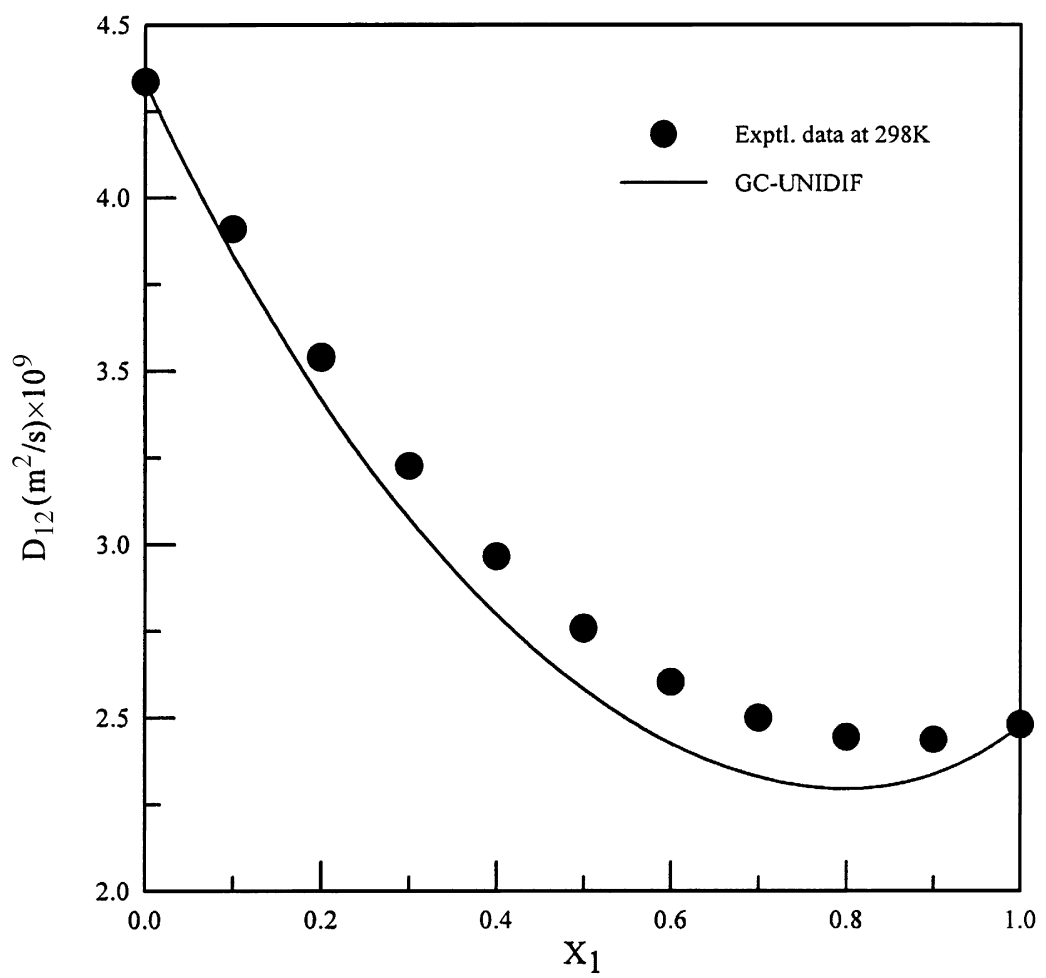

Fig. 9. Estimated results for the mutual diffusion coefficients of the binary mixture toluene (1)+n-hexane (2) at $298 \mathrm{~K}$. Data from [42]. 
model over 589 data points is $3.6 \%$. For the 61 binary systems tested in this study, 40 binary group interaction parameters are included, and these data are summarized in Table 3. It is also noticed that if other correlative methods are used, 122 binary parameters are required. As can be observed from Table 3 , more group interaction parameters need to be determined when further experimental data are available.

Using the generalized parameters in the GC-UNIDIF model, the mutual diffusion coefficients for another six binary systems are predicted and the results are shown in Table 4. The GC-UNIDIF model shows an overall deviation about $10 \%$. These six binary systems are not used in the regression of the generalized parameters. The result shows that the direct application of the group interaction parameters is feasible. Graphical presentations for the binary mixture of toluene and $n$-hexane at $298.15 \mathrm{~K}$ are shown in Fig. 9 with acceptable results.

\section{Conclusion}

A new GC-UNIDIF model for the mutual diffusion coefficients of binary liquid mixtures is developed in this study. This equation resembles the functional form of a UNIFAC equation and two temperature-independent group interaction parameters are included in the GC-UNIDIF model. The generalized group parameters of the GC-UNIDIF model for non-polar and polar mixtures are investigated. Satisfactory correlation results are presented for the GC-UNIDIF model. More group interaction parameters can be obtained when further experimental data are available.

$\begin{array}{ll}\text { List of symbols } \\ a & \text { interaction energy } \\ D & \text { diffusion coefficient } \\ h & \text { Planck's constant } \\ k & \text { Boltzmann's constant } \\ k_{\mathrm{a}} & \text { the frequency of movement } \\ m & \text { weight of a molecule } \\ n & \text { the number of components in a mixture } \\ N & \text { the number of molecules } \\ P & \text { pressure } \\ q & \text { surface area fraction } \\ T & \text { temperature } \\ U & \text { potential energy } \\ x & \text { mole fraction } \\ z & \text { coordination number } \\ & \\ G r e e k & \text { letters } \\ \phi & \text { the fraction of diffusion length, } \lambda \\ \lambda & \text { diffusion length } \\ \theta & \text { local composition parameter } \\ \tau & \text { interaction parameter } \\ \Omega & \text { the partition function of a liquid mixture } \\ \omega & \text { the number of configurations of a lattice }\end{array}$




\section{Superscripts}

$i_{0} \quad$ a state where $x_{i}$ is equal to 0

REF reference state

0 infinite dilution

\section{Subscripts}

$i, j \quad$ the property of component $i, j$

$m$ mixture property

\section{Acknowledgements}

The authors are grateful to the National Science Council for supporting this research.

\section{References}

[1] Y.D. Hsu, Y.P. Chen, Correlation of the mutual diffusion coefficients of binary liquid mixtures, Fluid Phase Equilibria 152 (1998) 149-168.

[2] M.A. Siddiqi, K. Lucas, Correlations for prediction of diffusion in liquids, Can. J. Chem. Eng. 64 (1986) $839-843$.

[3] R.K. Ghai, H. Ertl, F.A.L. Dullien, Liquid diffusion of nonelectrolytes: Part 1, AIChE J. 19 (1973) 881-900.

[4] E.L. Cussler, Cluster diffusion in liquids, AIChE J. 26 (1980) 43-51.

[5] H.T. Cullinan, An explicit formulation of the theory of cluster diffusion, AIChE J. 31 (1985) 1740-1741.

[6] D.K. Rollins, K.S. Knaebel, Applicability of Cullinan's equation for liquid binary diffusivities, AIChE J. 37 (1991) $470-474$.

[7] M. Pertler, E. Blass, G.W. Stevens, Fickian diffusion in binary mixtures that form two liquid phases, AIChE J. 42 (1996) 910-920.

[8] D.S. Abrams, J.M. Prausnitz, Statistical thermodynamics of liquid mixtures: a new expression for the excess Gibbs energy of partly or completely miscible systems, AIChE J. 21 (1975) 116-128.

[9] A. Fredenslund, R.L. Jones, J.M. Prausnitz, Group-contribution estimation of activity coefficients in nonideal liquid mixtures, AIChE J. 21 (1975) 1086-1099.

[10] W. Cao, A. Fredenslund, P. Rasmussen, Statistical thermodynamic model for viscosity of pure liquids and liquid mixtures, Ind. Eng. Chem. Res. 31 (1992) 2603-2619.

[11] W. Cao, K. Kundsen, A. Fredenslund, P. Rasmussen, Simultaneous correlation of viscosity and vapor-liquid equilibrium data, Ind. Eng. Chem. Res. 32 (1993) 2077-2087.

[12] W. Cao, K. Knudsen, A. Fredenslund, P. Rasmussen, Group-contribution viscosity predictions of liquid mixtures using UNIFAC-VLE parameters, Ind. Eng. Chem. Res. 32 (1993) 2088-2092.

[13] E.A. Guggenheim, Mixtures, Clarendon Press, Oxford, 1952.

[14] S. Glasstone, K.J. Laidler, H. Eyring, The Theory of Rate Processes, McGraw-Hill, New York, 1941.

[15] S.I. Sandler, Chemical Engineering Thermodynamics, Wiley, New York, 1999.

[16] R.L. Rowley, S.C. Yi, D.V. Gubler, J.M. Stoker, Mutual diffusivity, thermal conductivity, and heat of transport in binary liquid mixtures of alkanes in chloroform, J. Chem. Eng. Data 33 (1988) 362-366.

[17] R.L. Rowley, S.C. Yi, D.V. Gubler, J.M. Stoker, Mutual diffusivity, thermal conductivity, and heat of transport in binary liquid mixtures of alkanes in carbon tetrachloride, Fluid Phase Equilibria 36 (1987) 219-233.

[18] G.D. Wedlake, F.A.L. Dullien, Interdiffusion and density measurements in some binary liquid mixtures, J. Chem. Eng. Data 19 (1974) 229-235.

[19] D.L. Bidlack, D.K. Anderson, Mutual diffusion in nonideal, nonassociating liquid systems, J. Phys. Chem. 68 (1964) 3790-3794.

[20] M.V. Kulkarni, G.F. Allen, P.A. Lyons, Diffusion in carbon tetrachloride-cyclohexane solutions, J. Phys. Chem. 69 (1965) 2491-2493. 
[21] W. Hayduk, S. Ioakimidis, Liquid diffusivities in normal paraffin solutions, J. Chem. Eng. Data 21 (1976) 255-260.

[22] W.F. Calus, M.T. Tyn, Temperature and concentration dependence of diffusion coefficient in benzene- $n$-heptane mixtures, J. Chem. Eng. Data 18 (1973) 377-380.

[23] K.R. Harris, C.K.N. Pua, P.J. Dunlop, Mutual and tracer diffusion coefficients and frictional coefficients for the systems benzene-chlorobenzene, benzene- $n$-hexane, and benzene- $n$-heptane at $25^{\circ} \mathrm{C}$, J. Phys. Chem. 74 (1970) 3518-3529.

[24] T.M. Aminabhavi, P. Munk, Diffusion coefficients of some nonideal liquid mixtures, J. Phys. Chem. 84 (1980) $442-446$.

[25] L. Rodwin, J.A. Harpst, P.A. Lyons, Diffusion in the system cyclohexane-benzene, J. Phys. Chem. 69 (1965) $2783-2785$.

[26] S.A. Sanni, C.J.D. Fell, H.P. Hutchison, Diffusion coefficients and densities for binary organic liquid mixtures, J. Chem. Eng. Data 16 (1971) 424-427.

[27] D.W. McCall, D.C. Douglass, Diffusion in binary solutions, J. Phys. Chem. 71 (1967) 987-997.

[28] S.A. Sanni, H.P. Hutchison, Diffusivities and densities for binary liquid mixtures, J. Chem. Eng. Data 18 (1973) $317-322$.

[29] D.K. Anderson, A.L. Babb, Mutual diffusion in non-ideal liquid mixtures. III. Methyl ethyl ketone-carbon tetrachloride and acetic acid-carbon tetrachloride, J. Phys. Chem. 66 (1962) 899-901.

[30] V. Sanchez, M. Clifton, Mutual diffusion in binary mixtures of carbon tetrachloride and alcohols at $25^{\circ} \mathrm{C}$, J. Chem. Eng. Data 23 (1978) 209-212.

[31] D.K. Anderson, J.R. Hall, A.L. Babb, Mutual diffusion in non-ideal binary liquid mixtures, J. Phys. Chem. 62 (1958) 404-409.

[32] C.M. Kelly, G.B. Wirth, D.K. Anderson, Tracer and mutual diffusivities in the system chloroform-carbon tetrachloride at $25^{\circ}$ C, J. Phys. Chem. 75 (1971) 3293-3296.

[33] W.M. Melzer, W. Baldauf, H. Knapp, Measurement of diffusivity, viscosity, density and refractivity of eight binary liquid mixtures, Chem. Eng. Progress 26 (1989) 71-79.

[34] A.Z. Tasic, B.D. Djordjevic, S.P. Serbanovic, D.K. Grozdanic, Diffusion coefficients for the liquid system acetone-cyclohexane at 298.15 K, J. Chem. Eng. Data 26 (1981) 118-120.

[35] C. Ramakanth, A.K. Mukherjee, T.R. Das, Diffusion coefficients for selected binary liquid systems: cyclohexane and $n$-alkyl alcohols, J. Chem. Eng. Data 36 (1991) 384-387.

[36] H.T. Cullinan, H.L. Toor, Diffusion in the three-component liquid system acetone-benzene-carbon tetrachloride, J. Phys. Chem. 69 (1965) 3941-3949.

[37] P.C. Carman, Self-diffusion and interdiffusion in complex-forming binary systems, J. Phys. Chem. 71 (1967) $2565-2573$.

[38] M.T. Tyn, W.F. Calus, Temperature and concentration dependence of mutual diffusion coefficients of some binary liquid systems, J. Chem. Eng. Data 20 (1975) 310-316.

[39] Z.J. Derlacki, A.J. Easteal, A.V.J. Edge, L.A. Woolf, Z. Roksandic, Diffusion coefficients of methanol and water and the mutual diffusion coefficient in methanol-water solutions at 278 and $298 \mathrm{~K}$, J. Phys. Chem. 89 (1985) 5318-5322.

[40] Y.E. Lee, S.F.Y. Li, Binary diffusion coefficients of methanol/water system in the temperature range $30-40^{\circ} \mathrm{C}$, J. Chem. Eng. Data 36 (1991) 240-243.

[41] G. Guarino, O. Ortona, R. Sartorio, V. Vitagliano, Diffusion, viscosity, and refractivity data on the systems dimethylformamide-water and $n$-methylpyrrolidone-water at $5^{\circ} \mathrm{C}$, J. Chem. Eng. Data 30 (1985) 366-368.

[42] F.O. Shuck, H.L. Toor, Diffusion in the three component liquid system methyl alcohol-n-propyl alcohol-isobutyl alcohol, J. Phys. Chem. 67 (1963) 540-545.

[43] R.K. Ghai, F.A.L. Dullien, Diffusivities and viscosities of some binary liquid nonelectrolytes at $25^{\circ}$ C, J. Phys. Chem. 78 (1974) 2283-2291.

[44] G. Ramprasad, A.K. Mukherjee, T.R. Das, Mutual diffusion coefficients of some binary liquid systems: benzene- $n$-alkyl alcohol, J. Chem. Eng. Data 36 (1991) 124-126. 